\title{
Economic Policy Uncertainty and Allocative Distortions*
}

\author{
Omrane Guedhami, Sattar Mansi, David Reeb, and Yukihiro Yasuda
}

December 14, 2021

\begin{abstract}
We introduce this special issue on Economic Policy Uncertainty (EPU) with a focus on how EPU affects allocative efficiency. We observe that EPU affects the market value of firms in about $37 \%$ of Fama-French 30 industries, but leads to lower investments in $90 \%$ of them. Allocation decisions in a market economy rely on signals from the capital market, which EPU distorts. This may cause increasing conflicts of interest between managers and investors. We highlight key studies in the EPU literature and then describe each paper in this special issue. We also provide suggestions for future research.
\end{abstract}

Keywords: Allocative efficiency, Economic policy uncertainty, Firm investments, Agency conflicts

JEL Classifications: G31, E61, G18, D61

\footnotetext{
* Guedhami is at the University of South Carolina, Mansi is at Virginia Tech, Reeb is at the National University of Singapore, and Yasuda is at Hitotsubashi University. The authors would like to thank Steven Davis (keynote speaker), Iftekhar Hasan (editor), Hitotsubashi University (conference host), and conference participants for comments and feedback that greatly improved the papers in this issue. Any remaining errors are our own.
} 


\section{Introduction}

Uncertainty about economic policy generally hampers economic growth by reducing corporate investments and hiring (Baker et al., 2012). Kang et al. (2014) find that economic policy uncertainty (EPU) depresses firm investment because it can increase managerial doubts about the costs of doing business and the magnitude of potential profits. Brogaard and Detzel (2015) find that governments may create an additional layer of uncertainty because they decide fiscal, regulatory, and monetary policy. Gulen and Ion (2016) note that the large drops in investment associated with EPU are more pronounced in government contractors and in firms that make irreversible investments. More specifically, EPU alters the relation between investments and the cost of capital (Nguyen and Phan, 2017; Drobetz et al., 2018), which suggests that it limits the growth of financially constrained firms. As prior research has shown, firms prefer to hold cash during times of policy uncertainty to meet future potential demands (Hanlon et al., 2017).

Although the lower levels of investment from EPU are well documented, studies have typically focused on the average effect. The more fundamental question is whether EPU causes allocative distortions in capital markets. Baker et al. (2016) (hereafter, BBD) show that policy uncertainty leads to greater stock price volatility, which is most pronounced in governmentdependent industries. They introduce a unique measure of EPU based on keyword frequency in ten major U.S. newspapers. Finance scholars find cross-sectional differences in EPU's effects based on firm size and financial constraints.

The studies in this special issue build on this notion and provide key additional evidence on the topic. We complement this special issue by looking at the industry implications of EPU. The market values and investment decisions of the Fama-French 12, 30, and 48 industries reveal 
that economic policy has very different allocative efficiency implications across different economic sectors.

Strikingly, EPU only has a meaningful valuation impact in 11 of the 30 Fama-French industries. Ten industries experience lower market valuations, as measured by the market-to-book ratio, with higher EPU. In contrast, one other industry exhibits pronounced increases in market valuations with greater EPU. This rather narrow valuation impact is quite surprising given the strong average effects on investments and liquidity documented in prior literature. A natural question is why the narrow impact on market value leads so many firms to reduce investments. Firms in $90 \%$ of the industries reduce their investments with increased EPU. Of course, negatively affected firms would reduce investments, which is consistent with stock price movements. Nevertheless, we observe reductions in industries where market value increases, decreases, and remains flat.

A fundamental issue in economics is how prices reflect all available information (Fama, 1970) and guide the more efficient allocation of resources (Koopmans, 1951). Financial markets serve as a means to increase investments in growing industries and decrease them in declining ones, using market values as signals (Wurgler, 2000). Firms with growing market values encourage managers to increase investments, while those with decreasing values usually reduce investments. Both managers within the firm, and managers of other firms, rely on these market signals to make firm investments and engage in merger and acquisition activity. Dow and Gorton (1997) observe that managers have substantial discretion in translating these price signals into investment levels. This discretion, however, is colored by their preferences and incentives (Heckerman, 1975). Consequently, the link between price efficiency and allocative efficiency is tenuous (Dow and Gorton, 1997). 
EPU increases forecast errors by market participants (Beckmann and Czudaj, 2017), making it difficult for managers to infer information about investments from prices and for investors to evaluate managers' investment choices. Managers in industries with unaffected or even increasing market values, who cannot diversify their human capital, react to EPU by limiting firm investments. But, because market prices have not deteriorated in these industries, any reductions serve to reduce idiosyncratic risk, or may stem from managers' systematic private information. Investors seem to find it difficult to differentiate between the two explanations for reduced investments. This leads to greater agency problems between investors and managers. In short, EPU increases the wedge between managers and owners about investment choices, leading to distortions in allocative efficiency. The growth of promising industries may therefore be reduced with greater EPU.

The remainder of this paper is organized as follows. Section 2 presents BBD's (2016) seminal measure of economic political uncertainty. It also discusses our data and provides summary statistics. Section 3 describes our industry-based empirical results, while Section 4 outlines the contributions of each paper in this special issue. Section 5 offers ideas for future research. Section 6 concludes.

\section{Data and statistics}

\subsection{Measuring economic policy uncertainty}

We employ the time-varying news-based policy uncertainty index developed by BBD (2016) to capture EPU. Using an automated search of the archives of a country's major newspapers, BBD (2016) quantifies the frequency of articles that contain key terms in three categories: economy, policy-related, and uncertainty. To account for differences in the volume of news over time and across newspapers, the frequency counts are scaled by the total number of 
articles in each newspaper-month. The series of article counts are then standardized to a unit standard deviation and aggregated across newspapers within each month, so that each country has one representative monthly index. Each country's EPU series is normalized to a mean of 100.

BBD (2016) confirms that the index captures the overall level of EPU and contains information distinct in scope from other indicators that measure general economic or political effects. In addition, their index provides a reliable measure of policy-induced economic uncertainty by conducting various validation tests, such as human audits of newspapers (to account for political slant), and a comparison with other measures of economic uncertainty. We define EPU as the natural logarithm of the average of BBD's (2016) monthly policy uncertainty index over the fiscal year.

\subsection{Measuring financial outcomes}

We examine the impact of EPU on several corporate financial outcomes. Firm Value is defined as the market-to-book ratio of assets (MTB), where the market value of assets is the market value of equity plus the book value of assets minus the book value of equity. Investments are capital expenditures scaled by lagged total assets. Profitability is the ratio of operating income to total assets. Sales Growth is a firm's increase in sales from the previous fiscal year.

\subsection{Control variables}

Our selection of firm-level controls is the standard set of variables used in prior literature. These include Size, the natural logarithm of total assets in millions of U.S. dollars; Tangibility, the weighted sum of receivables, inventory, capital, and cash scaled by total assets; Leverage, the ratio of long-term debt to total assets; Cap_Int, the ratio of property, plant, and equipment scaled by total assets; $M T B$, the market value of assets, which is the market value of equity plus the book 
value of assets minus the book value of equity; Cash-flow Volatility, the standard deviation of cash flow to total assets over five years; Return, the average cumulative return over the past twelve months; Stdev_Return, the standard deviation of cumulative returns over the past twelve months; Turnover, the twelve-month turnover of a firm's shares; and Age, as proxied for by the ratio of retained earnings to common equity. We use different control variables depending on the outcome variable.

\subsection{Data sources and sample construction}

Our sample comprises all firms in the Compustat North America and Compustat Global datasets. To examine the impact of EPU on industry-level financial outcomes, we first merge the Compustat data with BBD's (2016) EPU index. Then, for all variables, we compute the respective industry mean values by averaging across all observations that belong to each country $i$ 's FamaFrench 30-industry portfolio $j$ in year $t{ }^{1}$ We exclude firm-years for which Fama-French 30industry codes or other necessary data are missing. To minimize the influence of extreme observations, all firm-level variables are winsorized at the 1st and 99th percentiles before computing the industry means. Our full sample comprises 13,613 country-industry-year observations from twenty-two countries over the 1987-2016 period. ${ }^{2}$

\section{Empirical analysis}

To examine whether EPU affects financial outcomes uniformly across industries, we estimate the following model separately for each Fama-French 30-industry portfolio:

\footnotetext{
${ }^{1}$ The results are similar when we use Fama-French 12- or 48-industry classifications to compute the industry means.

${ }^{2}$ Depending on the model, the number of observations may differ because each model specification requires different variables to be non-missing.
} 


$$
\text { Financial Outcome }_{i j t}=E P U_{i t}+\sum \beta_{i j t} \text { Control variables }+\mu_{i}+\varepsilon_{i j t} \text {. }
$$

We use this specification to study the effect of EPU on four different dependent variables: Investments, Profitability, Sales Growth, and Firm Value. The unit of observation is country i's Fama-French 30-industry $j$. The independent variable of interest, $E P U$, is the policy-related economic uncertainty of country $i$ in year $t$. For Investments, Profitability, and Sales Growth regressions, we control for Size, MTB, Cash-flow Volatility, Return, Stdev_Return, and Turnover. For Firm Value regressions, we control for Size, Tangibility, Leverage, and Cap_Int. To mitigate concerns about potentially unobservable heterogeneity, in all regressions, we control for country fixed effects $\left(\mu_{i}\right)$ and cluster standard errors by country.

Figure 1 reports the results for the Investments specifications. To facilitate the comparability of the effects of policy uncertainty, we plot the loadings on EPU with 95\% confidence intervals. The figure shows that $90 \%$ of industries display negative point estimates on $E P U$ at the 5\% significance level. The results are largely consistent with prior literature (e.g., Julio and Yook, 2012; Gulen and Ion, 2016), which shows that policy uncertainty depresses corporate investment. Interestingly, investments in the Communication (FF21) and Personal and Business Services (FF22) industries are the most adversely affected by an increase in EPU. We find no evidence that EPU depresses investments in the Coal (FF18), Utilities (FF20), or Smoke (FF3) industries.

Figures 2 and 3 repeat the regression specifications in Figure 1 by replacing the outcome variable with Profitability and Sales Growth, respectively. The results suggest that $83 \%$ of industries observe a decline in profits, and $67 \%$ experience lower sales growth in response to an increase in EPU. Profitability is the most adversely affected for the Precious Metals, Non-Metallic, and Industrial Metal Mining (FF17) and Coal (FF18) industries. We also find that Communication 
(FF21) and Personal and Business Services (FF22) industries show the least growth in sales. This reduction in sales growth, however, does not seem to translate into declines in profits for the Communication (FF21) industry. In contrast, declines in sales growth are mirrored in the reductions in profitability for the Personal and Business Services (FF22) industry, suggesting that the effects of EPU are not uniform across industries.

In Figure 4, we re-estimate our baseline model by examining the effect of EPU on Firm Value. The results reveal a striking pattern. EPU has a significant impact on only $36 \%$ of industries, with $33 \%$ having lower valuations ${ }^{3}$ and $3 \%$ having higher valuations. The remaining $64 \%$ are not significantly affected.

This rather narrow impact on valuation is surprising. As Figures 2 and 3 show, 83\% of industries saw a decline in profits, and $67 \%$ experienced lower sales growth, in response to an increase in EPU. We thus expect firms to significantly reduce investments, and this is precisely what we observed in Figure 1 for $90 \%$ of industries. However, in Figure 4, that reduction does not correlate with declines in market valuation. The results show that a large share of industries did not experience reductions in valuation as their investments declined.

Overall, our evidence in Figures 1-4 suggests a disconnect between investment and market valuation across industries. This has important implications for capital market allocations, since EPU may distort the fundamental role of stock markets in guiding investment decisions.

\section{Special issue papers}

This special issue of the Journal of Financial Stability (JFS) includes six articles that were presented at the Economic Policy Uncertainty Around the World conference at Hitotsubashi

\footnotetext{
${ }^{3}$ The Printing and Publishing (FF5) and Restaurants, Hotels, Motels (FF28) industries show the greatest drops in value.
} 
University in Tokyo in 2018. After the conference, they went through the usual review process. They represent innovative research in important areas of international EPU. This special issue thus provides a solid foundation for future researchers. Interest in this rapidly growing area, both inside and outside academia, has been interdisciplinary, with much of the work undertaken by researchers from economics, finance, law, management, and accounting.

Next, we briefly outline the six important papers included in this special issue. For each paper, we highlight the importance of the questions posed to researchers, how it and other recent research advance our understanding of the area, and the questions that future research may wish to consider. Throughout, we stress the questions concerning EPU that public and private decisionmakers face. Shedding light on these questions would be instructive and have substantial payoffs.

The first paper, entitled "Economic policy uncertainty and cross-border mergers and acquisitions," by Paudal, Thapa, Koirala, and Aldhawyan, extends prior work in the U.S. on corporate investment and mergers and acquisition (Gulen and Ion, 2016; Nguyen and Phan, 2017; Bonaime et al., 2018). The authors investigate how cross-border acquisitions (CBAs) are affected by EPU in acquirer and target countries. They test whether the EPU of the investment destination matters more than that of the home country.

Using a sample of 138,050 CBA deals from 20 countries between 1997 and 2017, Paudal et al. find that a higher degree of EPU at home decreases the number and volume of inbound CBA deals. This effect is positively moderated by the host country's better quality of institutions, business environment, and political risk. The authors conduct a bilateral acquirer-target countrypair analysis. They show that, while higher EPU in the target country may deter inbound CBAs, higher EPU in the acquirer country is positively associated with a higher number and volume of outbound CBAs. These results are consistent with the view that high EPU encourages outbound 
acquisitions but discourages inbound acquisitions, because of the hedging and deterrence explanations, respectively. On the stock market announcement of the CBA deals, they find that targets (acquirers) based in countries with a large increase in EPU are associated with lower (more) stock returns than those in countries with a smaller increase in EPU. These results indicate that investors recognize the effects of EPU on deal synergies and reflect their belief in the stock price accordingly.

The second paper, entitled "Uncertainty of uncertainty and firm cash holdings," is by Goodell, Goyal, and Urquhart. Goodell et al. focus on how firms react to the uncertainty over future levels of uncertainty. Specifically, they examine the effect on firm cash holdings of the "uncertainty of uncertainty." Given rational expectations, Goodell et al. proxy for the ex-post volatility of the EPU index developed by BBD (2016). They conjecture that firm cash holdings will be larger in environments of greater model uncertainty about levels of uncertainty.

Goodell et al. use a large sample across twenty-two countries from early 1990 to 2017. They find that firms tend to hoard more cash when there is greater volatility of economic uncertainty. Interestingly, this volatility is a more important determinant of firm cash holdings than EPU itself. Thus, when including EPU as a control variable, its volatility is much more economically significant than policy uncertainty. Economically, the coefficient of uncertainty is roughly $5 \%$ larger than the coefficient on levels of uncertainty. These results are robust to a wide range of control variables, including firm characteristics, macroeconomic factors, national governance, and national culture.

The third article is entitled "The impact of political uncertainty on institutional ownership," by Francis, Hasan, and Zhu. The authors focus on whether and how political uncertainty, especially as it relates to scheduled major political events such as elections, influences institutional holdings 
of common equity. They also test whether a politically induced holding strategy reflects the information advantages of institutional investors.

Using a sample of 568,711 stock-quarter observations over the 1981-2010 period, Francis et al. find that institutions significantly reduce their stock holdings when they expect increased political uncertainty. For example, holdings during presidential election years are shown to decrease by $0.8 \%$ to $2.3 \%$. The negative impact is robust to several measures of policy uncertainty, including presidential elections, gubernatorial elections, and BBD’s (2016) Political Uncertainty Index. Francis et al. also test whether institutions' strategies are beneficial. By looking at excess returns associated with changes in ownership during election years, they find that institutions benefit from their holding strategies. They examine a subsample of American Depositary Receipts (ADRs) and find the effect is the opposite for ADRs. Collectively, their results show that holding strategies (holding changes) induced by political uncertainty reflect institutions' information advantages.

The fourth article, entitled "Earnings management and Economic policy uncertainty: Evidence from Japan," is by Kim and Yasuda. The authors examine how policy uncertainty affects earnings management decisions at the firm level. They argue for two conflicting views. On the one hand, El Ghoul et al. (2020) find that firms reduce earnings management when EPU is high. They find that increased attention from market participants is a mechanism through which EPU affects earnings management. On the other hand, greater policy-induced uncertainty may create more opportunities for "window dressing," as information asymmetries between managers and investors become more acute (Schipper, 1989).

Yung and Root (2019) support the view that firms increase earnings management when EPU is high. While their results are obtained in multi-country analyses, Kim and Yasuda provide 
evidence on the net effects of policy uncertainty on earnings management within a single country. They focus on the monitoring role of a firm's main bank, and note that Japanese banks may hold equity stakes in non-financial firms. They use the economic policy constructed by Arbatli et al. (2017), which is based on BBD's (2016) study using representative Japanese newspapers.

Using a sample of 60,056 firm-year observations from 1997 to 2018 in Japan, Kim and Yasuda also document that managers have incentives to reduce earnings management when EPU is high. They find that the relation is less pronounced for firms with a main bank relationship. These results are consistent with the view that banks' monitoring role is effective in normal times, resulting in fewer opportunities to reduce earnings management when EPU is high (i.e., a moderating effect). Similar qualitative results are found when focusing on firms with (versus those without) analyst coverage.

The fifth article is entitled "Doing good in periods of high uncertainty: Economic policy uncertainty, corporate social responsibility and analyst forecast error," by Chahine, Daher, and Saade. Because policy uncertainty hinders economic and market activity, it increases market volatility and negatively affects corporate outcomes (Gulen and Ion, 2016; Dai and Ngo, 2020). Prior research has established that higher uncertainty affects the quality of public information, leading investors to demand additional material from financial analysts. Analysts are therefore more likely to supplement the information that could improve their forecasts (Ramnath et al., 2008). The disclosure of CSR-related non-financial information has recently emerged as a novel source for analyst forecasts. Chahine et al. argue that CSR plays an informational role that allows analysts to better assess firm performance. They examine whether good CSR practices can mitigate the detrimental effects of policy uncertainty on the accuracy of analyst forecasts. 
Using a large sample of observations from 2004-2013, Chahine et al. investigate the effect of policy uncertainty on analysts' forecasts of corporate earnings. They find that EPU is positively associated with analyst forecast error. Economically, a doubling of EPU results in a $0.8 \%$ increase in analyst forecast error. They also examine the role of CSR in the relation between policy uncertainty and the accuracy of analyst earnings forecasts, finding that CSR scores mitigate any negative impact. This implies that CSR can play a stabilizing role by moderating analyst forecast error during times of high policy uncertainty. Additionally, Chahine et al. find that the moderating role of CSR is more pronounced for domestic than multinational companies.

The sixth paper, entitled "Connected banks and Economic Policy Uncertainty," is by Chen, Gawande, Ongena, and Shusen. The literature has found that EPU leads banks to reduce loans, experience more non-performing loans, and change pricing. Against this backdrop, Chen et al. address the relation between political connections and the effect of policy uncertainty on bank loan volume and loss provisions. They examine the role of political connections in mitigating the detrimental impact of policy uncertainty on banks. Chen et al. also use BBD's (2016) EPU index. To identify banks' political connections, they investigate whether a bank is headquartered in a state with a senator on the Senate Banking Committee. The idea is that each state is represented by two senators, but all senators have the same power to assist the banks headquartered in their home states. They also argue that Senate Banking Committee representation is a proper measure of bank political connections.

Chen et al. use a sample of 877,448 bank-quarter observations, including all commercial banks and savings institutions in the U.S. from 1985 to 2013. They find that banks are more cautious when facing policy uncertainty, but the effect may be eased somewhat when banks are politically connected. A 1-standard deviation increase in EPU increases banks' loss provision-to- 
loan volume ratio by $15 \%$. In contrast, connected banks maintain an almost $7 \%$ lower ratio than non-connected banks. The authors also find that the mitigating role of political connections is driven primarily by smaller banks, and by periods of stricter bank regulations.

To conclude, the six articles in this issue are excellent examples of current international research in economic policy uncertainty. We hope that this introduction to the datasets, methodological challenges, and research in this area will propel more research in this interesting and promising field.

\section{Future research}

Although the studies in this special issue provide new insights into the causal impact of uncertainty on firms and the real economy, we still know relatively little about how policy-induced economic uncertainty influences the decision-making of financial institutions and corporations. This is an important issue in an increasingly integrated and globalized world. Global corporations play a vital role in economic growth and the transmission between host and domestic countries. Therefore, we must further our understanding of how and to what extent business strategies, structures, and decision-making change according to levels of EPU, and whether global corporations contribute to its proliferation around the world.

The goal of this conference and the special issue was to encourage innovative research that will deepen theoretical and empirical insights into EPU. We aimed to study how it may influence corporate policies and the performance of financial institutions and/or corporations, as well as the impact of the institutional environment in moderating or enhancing such relations. Several topics emerged that could provide fertile ground for future studies: 
- What is the role of domestic and global EPU in influencing the operating and entry strategies of multinational corporations (MNCs)?

- What is the effect of policy uncertainty and its dimensions on the sensitivity of corporate policies to stock price and overall performance?

- Can firms use operational (e.g., diversification) and financial (e.g., derivative products) approaches to hedge against EPU?

- What factors influence the exposure of corporations to policy uncertainty?

- What are the roles of a country's legal, political, and cultural environments in affecting the relations between policy uncertainty and corporate policies and performance?

- Do the effects of EPU vary across emerging and developed markets' corporations? What explains these differences?

- What is the role of ownership structure on the relation between policy uncertainty and corporate policies? How are different types of owners (family, state, and institutional owners) affected by policy uncertainty?

- What are the characteristics of corporations that are more vulnerable to domestic versus global EPU?

- Do MNCs contribute to propagating the effects of EPU across countries? What are the implications for global financial stability?

We believe each topic represents important issues that should be addressed with common theoretical tools and careful research designs.

\section{Conclusion}


It is well recognized that capital markets serve to allocate resources. Grossman (1995) observes that price changes enable exchanges among investors and ultimately allocate resources to more efficient uses. Market values, scaled by book value, help managers and investors distinguish between good and bad investment opportunities (Wurgler, 2000). Allocative efficiency, however, depends on managers assimilating this public information about their firms' market value with their private information to make investment decisions. Thus, internal investment decisions are partially driven by changes in stock prices.

The merger and acquisition market also relies on signals from market prices that are serving to reallocate capital from less efficient to more efficient uses. The analysis and findings in this special issue point to the potential for more forecast errors about firms' future operations because of EPU. This is because market prices or values give less precise signals about firm operations in the presence of greater EPU. Chahine et al. demonstrate this by examining the effect on financial analysts' forecasts.

Professional managers exercise their discretion in choosing the firm's investment level by translating these price signals and their private information about the firm into each firm's level of investment. Managers' decisions, however, may also be influenced by their own incentives. Because managers cannot diversify their human capital, which is often their greatest asset, they need to be concerned with both idiosyncratic and systemic firm risk. EPU increases both types (Brogaard and Detzel, 2015; Ashraf and Shen, 2019). Undiversified managers face substantial firm risk, which may give them powerful incentives to reduce investments even if price signals do not warrant it. Reducing investments and hoarding cash both lower managerial risk during periods of EPU. Investors have greater difficulty monitoring managerial investment choices in this scenario, 
because the price signals are less precise. Therefore, because EPU also affects managers' private information, it may reduce allocative market efficiency.

Monitoring by investors depends on their ability to use these price signals to evaluate managerial investment choices. However, because EPU increases forecast errors, it weakens that ability. The merger and acquisition market also serves as a check on poor investment decisions. But the impact of EPU on market prices tends to decrease M\&A activity. Bonaime et al. (2018) show that this occurs within domestic markets, while Paudal et al. show that EPU affects international markets as well. Taken together, this evidence suggests that EPU disrupts withinfirm investments and monitoring. It creates greater incentives for investment distortions and decreases the ability to monitor and discipline managers. Consistent with this idea, we find that EPU only affects the market-to-book ratio for 11 of the Fama-French 30 industries. Firms in 27 of these industries are shown to have reduced their investments, although prices did not necessarily decline.

Allocative efficiency refers to getting the right assets to the right place in a timely fashion. It thus depends somewhat on the speed with which assets can be moved from poorly deployed projects to higher-use operations. The evidence in this special issue indicates that EPU reduces the speed at which resources are effectively reallocated. Firms therefore cannot operate as efficiently during periods of EPU. This leads to underinvestment in the best-performing sectors. 


\section{References}

Arbatli, E. C., Davis, S. J., Ito, A., Miake, N., Saito, I., 2017. Policy uncertainty in Japan. National Bureau of Economic Research. Working paper.

Ashraf, B. N., Shen, Y., 2019. Economic policy uncertainty and banks' loan pricing. Journal of Financial Stability. 44, 100695.

Baker, S., Bloom, N., Davis, S. J., 2012. Has economic policy uncertainty hampered the recovery within Government Policies and the Delayed Economic Recovery, edited by Lee Ohanian, John B. Taylor and Ian Wright, Hoover Institution Press.

Baker, S. R., Bloom, N., Davis, S. J., 2016. Measuring economic political uncertainty. Quarterly Journal of Economics. 131(4), 1593-1636.

Beckmann, J., Czudaj, R., 2017. The impact of uncertainty on professional exchange rate forecasts. Journal of International Money and Finance. 73, 296-316.

Bonaime, A., Gulen, H., Ion, M., 2018. Does policy uncertainty affect mergers and acquisitions? Journal of Financial Economics. 129(3), 531-558.

Brogaard, J., Detzel, A., 2015. The asset-pricing implications of government economic policy uncertainty. Management Science. 61(1), 3-18.

Dai, L., Ngo, P., 2020. Political uncertainty and accounting conservatism. European Accounting Review. 1-32.

Dow, J., Gorton, G., 1997. Stock market efficiency and economic efficiency: Is there a connection? Journal of Finance. 52(3), 1087-1129.

Drobetz, W., El Ghoul, S., Guedhami, O., Janzen, M., 2018. Policy Uncertainty, Investment, and the Cost of Capital. Journal of Financial Stability. 39, 28-45.

El Ghoul, S., Guedhami, O., Kim, Y., Yoon, H. J., 2020. Policy uncertainty and earnings management. The Accounting Review. Forthcoming.

Fama, E. F., 1970. Efficient Capital Markets: A Review of Theory and Empirical Work. Journal of Finance. 25(2), 383-417.

Grossman, S. J., 1995. Dynamic asset allocation and the informational efficiency of markets. Journal of Finance. 50(3), 773-787.

Gulen, H., Ion, M., 2016. Policy uncertainty and corporate investment. Review of Financial Studies. 29(3), 523-564.

Hanlon, M., Maydew, E. L., Saavedra, D., 2017. The taxman cometh: Does tax uncertainty affect corporate cash holdings? Review of Accounting Studies. 22(3), 1198-1228. 
Heckerman, D. G., 1975. Motivating managers to make investment decisions. Journal of Financial Economics. 2(3), 273-292.

Julio, B., Yook, Y., 2012. Political uncertainty and corporate investment cycles. Journal of Finance. 67(1), 45-83.

Kang, W., Lee, K., Ratti R.A., 2014. Economic policy uncertainty and firm-level investments, Journal of Macroeconomics. 39, 42-53.

Koopmans, T. C., 1951. An analysis of production as an efficient combination of activities. In: T.C. Koopmans (Ed.), Activity Analysis of Production and Allocation, Cowles Commission for Research in Economics. Mono-graph, No.13, Wiley, New York.

Nguyen, N. H., Phan, H. V., 2017. Policy uncertainty and mergers and acquisitions. Journal of Financial and Quantitative Analysis. 52(2), 613-644.

Ramnath, S., Rock, S., Shane, O., 2008. The financial analyst forecasting literature: A taxonomy with suggestions for further research. International Journal of Forecasting. 24, 34-75.

Schipper, K., 1989. Earnings management. Accounting horizons. 3(4), 91.

Wurgler, J., 2000. Financial markets and the allocation of capital. Journal of Financial Economics. 58, 187-214.

Yung, K., Root, A., 2019. Policy uncertainty and earnings management: International evidence. Journal of Business Research. 100, 255-267. 
Figure 1. EPU and Investment

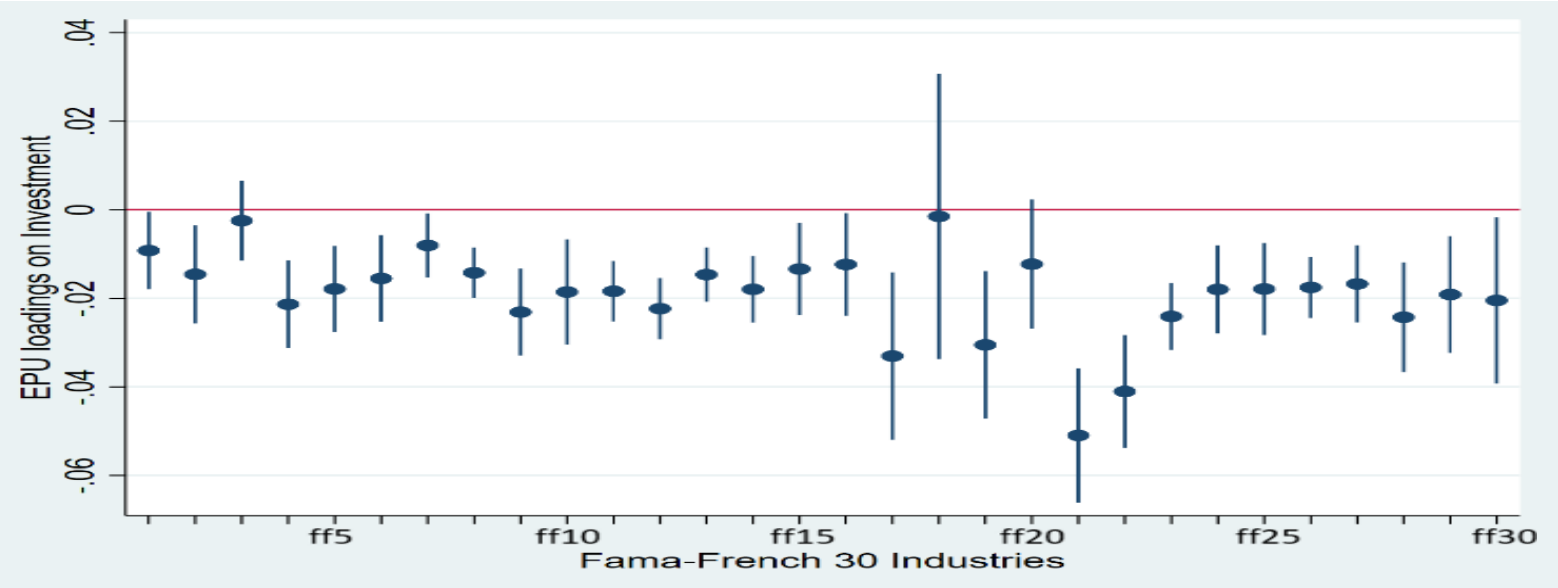

Figure 2. EPU and Profitability

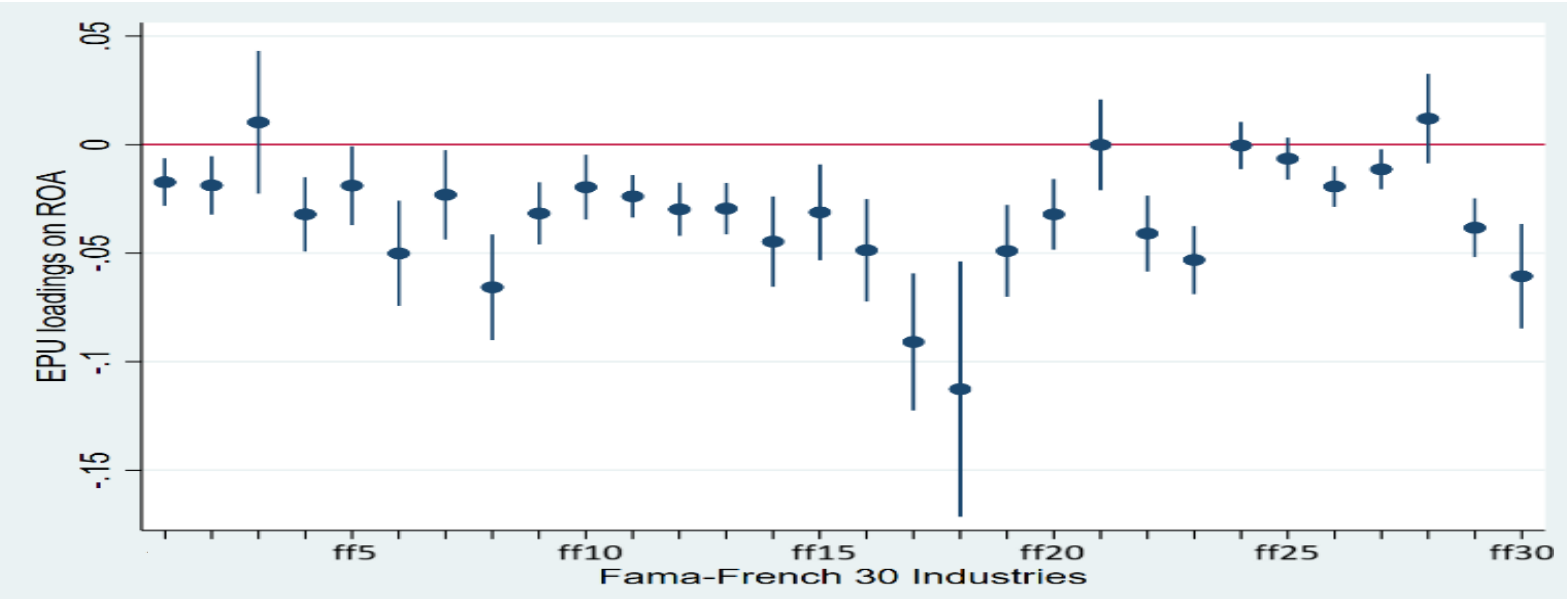

Figure 3. EPU and Sales Growth 


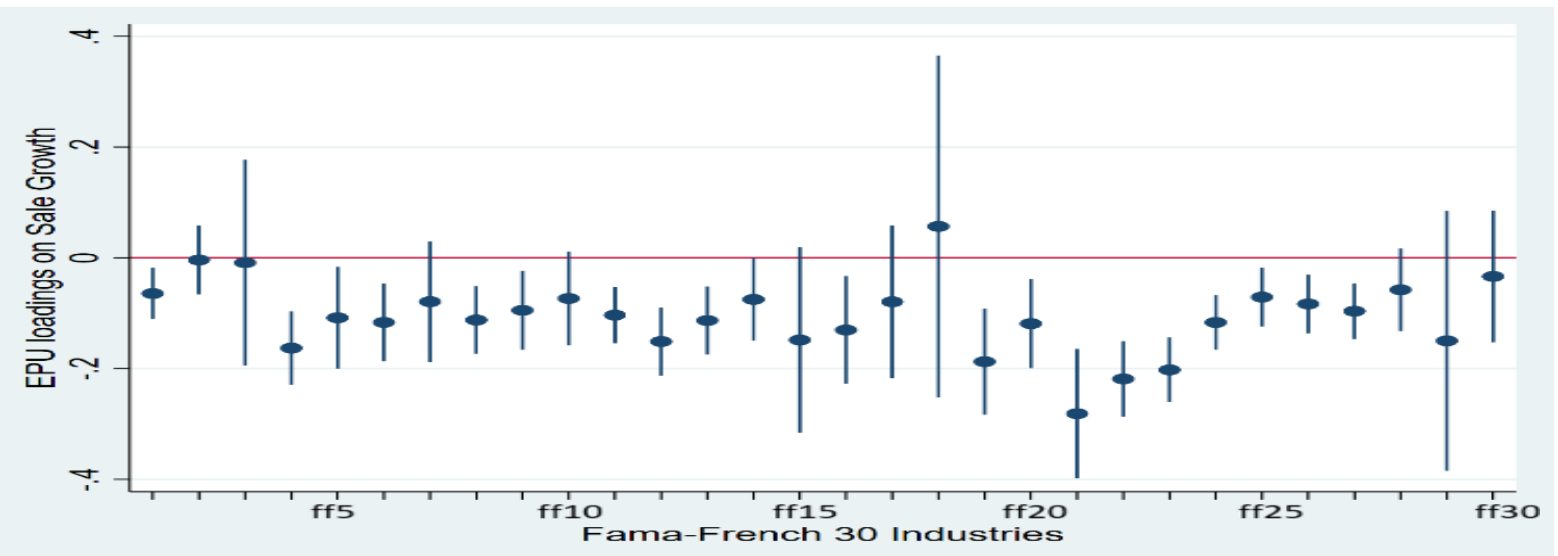

Figure 4. EPU and Valuation

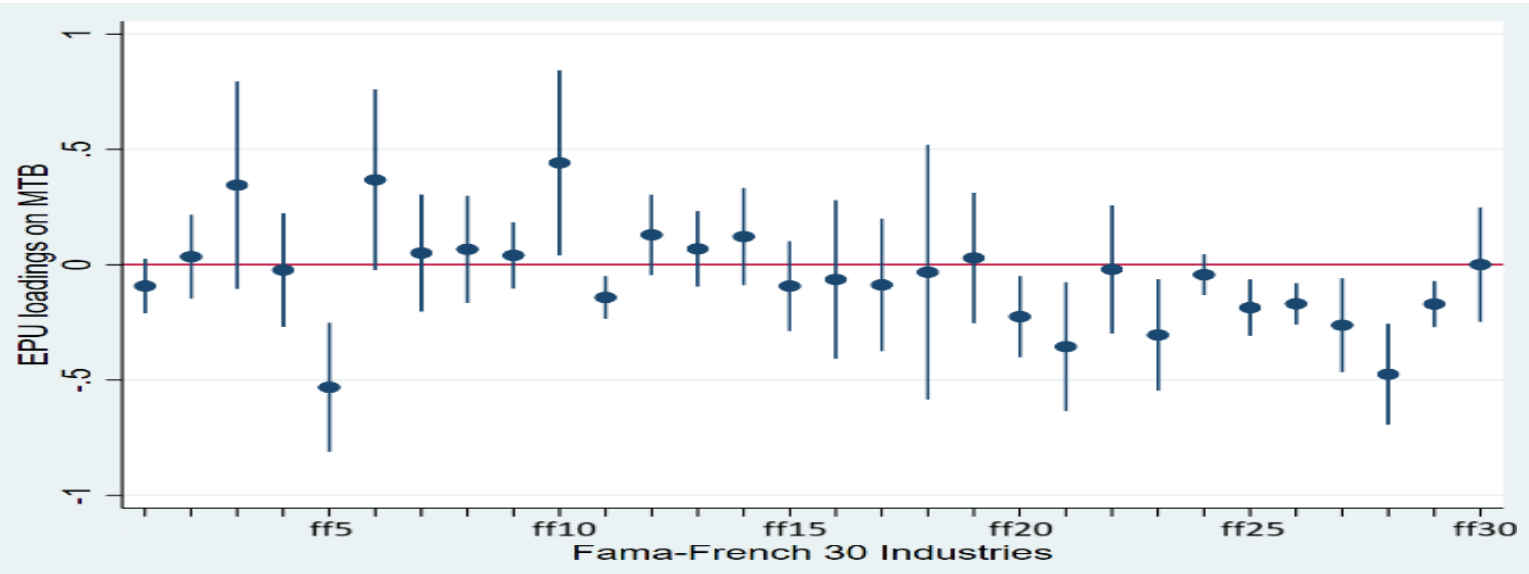

